\title{
A SECOND HELPING
}

Surely, research is often somewhat Olympian. In one popular conception researchers dwell in ivory towers and discuss among themselves problems of such divine abstraction that we, the common breed who are footing the bill after all, despair. Indeed, it is rumoured that there is not even discussion, just a soliloquy within the ivoryhoused researchers. It is also bruited about that when they descend from snow-bound Olympus they are certain to misinterpret mortal affairs or overclaim the impact of their cogitations on the common lot of humanity.

The previous century offers luscious examples. In 1828 one Wöhler found that urea, considered to be organic because you and I excrete it, could be synthesized from its inorganic isomer, ammonium cyanate. He promptly burst forth: "I reserve the field of organic synthesis from inorganics to myself in perpetuity."

Not so our database researchers. True, they have pursued their labours in perfect disregard of applicability, which, incidentically, they have not even claimed. Driven by curiosity and nothing much else, these Olympians have solved, in etherial abstraction and with mundane thoroughness, such inapplicable questions as Can two Bishops win against a Knight? One suspects that the question was at least as fascinating to them as many others because its applicability was so limited. Searching the literature from Wöhler's time to ours has brought to light less than a handful of potential applications of Ken Thompson's Olympian research into KBBKN.

But even Olympian knowledge, once it is known to exist, is bound to percolate to the humdrum human level. Indeed, the very fact that some Olympian literally knows all about an endgame database may tempt a human master into reducing his own game to a position decidable by such an endgame. When considering doing so, he is a prey to conflicting emotions: while he may gain advance knowledge of the predestined outcome between perfect players, which may cheer him when he is assured a win, he is also, being human, awed by the Olympian knowledge and wonders whether he can play up to the Olympian standard. Those folks on Olympus have their own way of moving which we, poor mortals, cannot hope to assimilate.

\section{TABLE OF CONTENTS}

Table of Contents

A Second Helping (I.S. Herschberg and H.J. van den Herik) ................................................................ 1

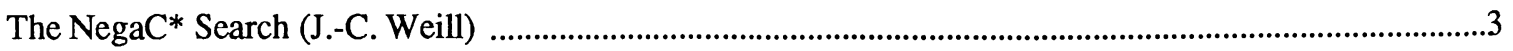

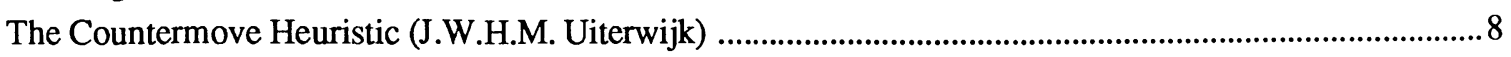

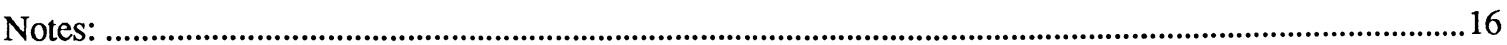

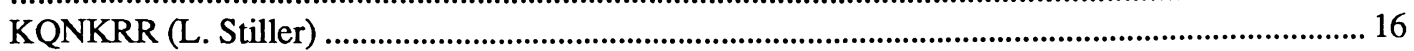

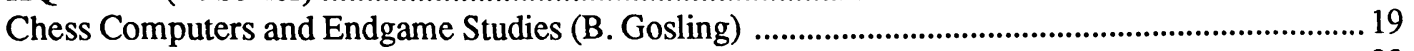

On Asymmetries in Chess Programs (I. Althöfer) ............................................................................ 23

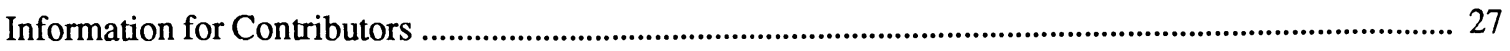

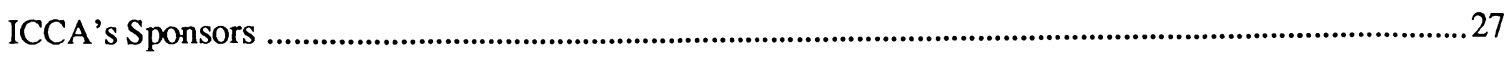

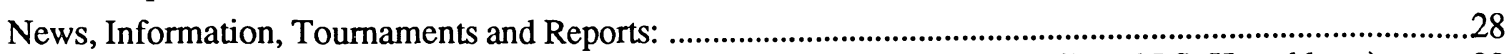

A Database as a Second (D.M. Breuker, L.V. Allis, H.J. van den Herik and I.S. Herschberg) ........ 28

Before Databases (D.N.L. Levy and H.J.J. Nefkens) .......................................................................4 40

The Swedish Rating List (T. Karlsson and G. Grottling) ................................................................. 43

Calendar of Computer-Chess Events ............................................................................................44

The $7^{\text {th }}$ World Computer Chess Championship (Madrid) .................................................................4 44

The $12^{\text {th }}$ World Microcomputer Chess Championship ....................................................................44

The AST Computer Olympiad and the AST Conference on Computer Games (London) .............. 45

The 1992 AEGON Man-Computer Tournament (The Hague) .......................................................... 47

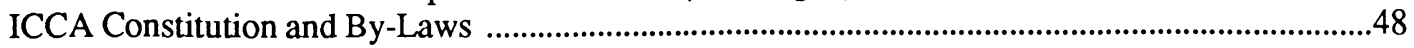

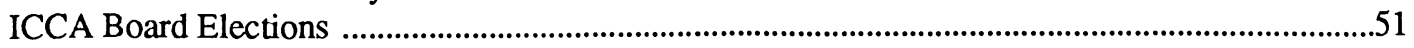

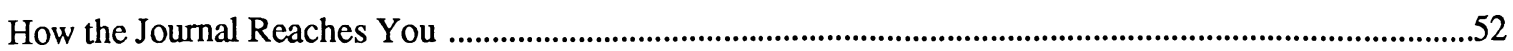


Our fable applies to Ken Thompson, an Olympian if ever there was, a world-class tournament and Jan Timman. Ken Thompson, a true dweller on high, had chucked his database at an unsuspecting and possibly largely incurious world, had it not been for Roycroft who tried to find rhyme and reason in the convolutions of Ken's researches and duly published them.

Now when Jan Timman, definitely sympathetic to computer aid, found himself in a position to reduce his board to a pure instance of KBBKN, the wires started humming. From Linares to your Editor-in-Chief a request for facts was transmitted, answered promptly by as much informfation as Timman requested and possibly somewhat more. It was all duly processed: not that Timman, by his own confession, had absorbed all of its nitty-gritty, but, we are proud to state, he had at least assimilated as much knowledge as would stand him in very good stead when resuming his adjourned game against Speelman.

Speaking on behalf of the International Computer-Chess Community, we claim modestly that Timman had some help from Thompson, Roycroft and your Editor-in-Chief. For the very least, the assistance thus provided was the equivalent of the thoughtful ministrations of a second. Moreover, we believe the second in question was altruistic to a fault and objective to perfection. And what can be wrong, ethically, with such a second helping? Surely as little as poor Oliver Twist can be faulted for requiring his. A second helping should be allowed when fair is fair.

Bob Herschberg Jaap van den Herik

Owing to circumstances beyond computer control, the coordinates of the Editor-in-Chief and his secretarial staff are in a state of flux.

As from May 6, 1992 the telephone number is

$$
\begin{aligned}
& +3143883477 \text {, or } \\
& +3143883485 \text { if the above should fail to answer, }
\end{aligned}
$$

the residential address remaining at Bredestraat 24, $6211 \mathrm{HC}$ Maastricht.

As from October 1, 1992 there is a change of venue, the new premises being

$$
\begin{aligned}
& \text { Kapoenstraat } 2 \\
& 6211 \text { KW Maastricht } \\
& \text { The Netherlands }
\end{aligned}
$$

It is consoling to record that the Fax number and the Email address will remain unchanged as

$$
+3143252392
$$

icca@cs.rulimburg.nl 